\title{
Gender and growth variation in palatal bone thickness and density for mini-implant placement
}

\author{
Sumit Yadav ${ }^{1,2^{*}}$, Emily Sachs ${ }^{2}$, Meenakshi Vishwanath ${ }^{3}$, Kristen Knecht ${ }^{4}$, Madhur Upadhyay ${ }^{1}$, Ravindra Nanda ${ }^{1}$
} and Aditya Tadinada ${ }^{5}$

\begin{abstract}
Background: The objective was to compare the palatal bone thickness (PBT) and palatal bone density (PBD) in the anterior, middle, and posterior part of the palate in males and females.

Methods: This retrospective study reviewed cone beam computed tomography scans of 359 patients. The scans were divided into 99 growing males, 105 growing females, 74 non-growing males, and 81 non-growing females. The measurements of PBT and PBD were made in between the canine and first premolar, the first premolar and second premolar, the second premolar and first molar, and the first molar and second molar. The measurements were made in the center of the palate and $4 \mathrm{~mm}$ away from the center. ANOVA was used to analyze the PBT and PBD in different areas between four different groups.
\end{abstract}

Results: The PBT was lower $(P<0.0001)$ as we moved from the anterior to the posterior palate. The PBT was more $(P<0.001)$ in the center of the palate than $4 \mathrm{~mm}$ away from the center, except in between the canine and first premolar. The growing male and non-growing male had higher $(P<0.0001)$ PBT than the growing female and non-growing female in between the canine and first premolar and the first premolar and second premolar both in the center and $4 \mathrm{~mm}$ away from it. The PBD was higher $(P<0.05)$ in between the canine and first premolar area at the center of the palate and between the second premolar and first molar $4 \mathrm{~mm}$ away from the center in all the experimental groups.

Conclusions: There exists a definite gender and growth variation in the PBT and PBD in different parts of the palate. Palatal bone thickness between the males and females revealed that the males had significantly higher PBT than the females.

\section{Background}

In the recent years, palatal mini-implants have gained popularity and have been widely used for molar intrusion, molar protraction, segment protraction, and anterior tooth retraction [1-7]. The palatal mini-implants are usually preferred, because the site of mini-implant placement is easily accessible, has less soft tissue irritation, does not interfere with the desired orthodontic tooth movement, and has good quality and quantity of bone

\footnotetext{
*Correspondence: Yadav_sumit17@yahoo.com

'Division of Orthodontics, University of Connecticut Health Center, Farmington, USA

${ }^{2}$ School of Dental Medicine, University of Connecticut Health Center, 263

Farmington Avenue, L7062A MC1725, Farmington, CT 06030, USA

Full list of author information is available at the end of the article
}

$[8,9]$. The palatal mini-implants are commonly inserted in the anterior region of the palate, mid-palatal area, and the posterior region of the palate $[9,10]$. The success of the mini-implants usually depends on the bone quantity (bone volume/amount of bone present) and bone quality (bone density). Bone quality and quantity can be influenced by many factors, including heredity, race, environment, nutrition, and lifestyle [11-13].

The success of mini-implants usually depends on the degree to which it integrates (mechanically and biologically) with the host bone. The palatal bone thickness and palatal bone density vary at different mini-implant insertion sites in the palate, and the appropriate knowledge of the amount of bone available (bone thickness/bone volume) and amount of bone 
mineralization (bone mineral density) should guide orthodontic clinicians to make educated decisions in selecting the mini-implant placement site. The mineral content of the bone matrix and heterogeneity of mineralization are important factors to assess the quality of bone. Palatal mini-implants have shown excellent stability. Karagkiolidou et al. showed that approximately $98 \%$ of mini-implants are stable, when they are inserted in the anterior region of the palate [14]. Manni et al. showed that the failure risk of mini-implants is significantly more in females when compared to males [15].

Three-dimensional imaging using cone beam computed tomography provides a method to characterize the bone quantity and bone mineral density (bone quality) $[16,17]$. Studies have shown that cone beam computed tomography (CBCT) can be used for assessing the bone quantity and quality (bone mineral density) of the maxillary and mandibular bones $[17,18]$. Bone mineral density is usually assessed in 3D imaging by evaluating the gray levels of the CBCT images [19-22]. It has been well documented that there exist a gender variation between the bone quantity and bone quality $[19,23]$. Moreover, it has been shown that an adult (non-growing) has more bone mineral density than growing people [23].

Studies have assessed either the bone quality or the bone quantity individually; to our knowledge, our study is the first study to assess the bone quality and bone quantity in the same patients $[1,4,24,25]$. Our objective is to measure the palatal bone thickness and palatal bone density at different sites in the palate (in the center of palate and $4 \mathrm{~mm}$ away from the center) in a population of growing and non-growing Caucasian subjects, who previously received CBCT scans for orthodontic treatment. Additionally, our aim is to compare and contrast the palatal bone thickness and palatal bone density between males (growing males vs. non-growing males) and females (growing females vs. non-growing females). Our null hypothesis is that the palatal bone thickness and palatal bone density at different sites is not different between males and females.

\section{Methods}

An institutional review board exemption was obtained for evaluating CBCT volumes archived in the Department of Oral and Maxillofacial Radiology. This retrospective study reviewed 359 CBCT scans of patients who were referred for orthodontic treatment. All CBCT scans were acquired using the iCAT Next Generation (Imaging Sciences International, Hatfield, $\mathrm{Pa}$ ) CBCT unit. A standardized protocol of the iCAT for the extended $(17 \times 23 \mathrm{~cm})$ field of view (FOV) with $0.3-\mathrm{mm}$ slice thickness and 26.9-s acquisition time was used. All scans were saved in the DICOM-3 format and were evaluated using a third party $\mathrm{CBCT}$ reconstruction software InVivo5.0 (Anatomage, San Jose, CA). On the basis of age, the scans were divided into four groups: group 1, growing male; group 2, growing female; group 3, non-growing male; and group 4, non-growing female. The exclusion criteria were (1) cases with congenitally missing teeth; (2) CBCT scans showing supernumerary teeth, enlarged/cystic follicle, or any other pathology; (3) CBCT scans showing no systemic disease affecting the bone of the patients; and (4) CBCT scans showing impacted teeth in the area of the measurement. These exclusion criteria were set, as these might have affected the palatal one thickness (PBT) and the palatal bone density (PBD).

All CBCT volumes were imported into Invivo5 (Ver. 5.3) (Anatomage Inc., CA) software, and a single examiner reviewed all the scans independently. The investigators reviewed the images on a split screen dual display monitor (HP Compaq LA2205wg) under standardized conditions of ambient light and sound. The investigators had the full capability to evaluate the volumes in all the three orthogonal planes and manipulate contrast and histogram. Once the scans were imported into the reconstruction program, all scans were aligned parallel to Frankfort's horizontal plane. The scans were then aligned in the field of view on axial sections to be in the center of the palate using the incisive foramen as a standardized landmark (Fig. 1). Once the center was established on all the three planes (axial, sagittal, and coronal) using the toggled cross hairs in the program, PBT was measured. The measurements of PBT were made in between the canine and first premolar, between the first premolar and second premolar, between the second premolar and first molar, and between the first molar and second molar (Fig. 2a). The measurements were made in the center of the palate and $4 \mathrm{~mm}$ sequentially away from the center of the palate (Fig. 2a).

The measurements of PBD were made in between the canine and first premolar, between the first premolar and second premolar, between the second premolar and first molar, and between the first molar and second molar. Using the Hounsfield unit (HU) equivalent pixel intensity value scale in the software program, density values were recorded in the center of the palate (Fig. 2b). To test the intraexaminer reliability, 20 randomly selected scans were measured 4 weeks later by the same person both for PBT and PBD.

\section{Statistical approach}

Descriptive statistics were used to summarize the outcomes (palatal bone thickness and palatal bone density). 


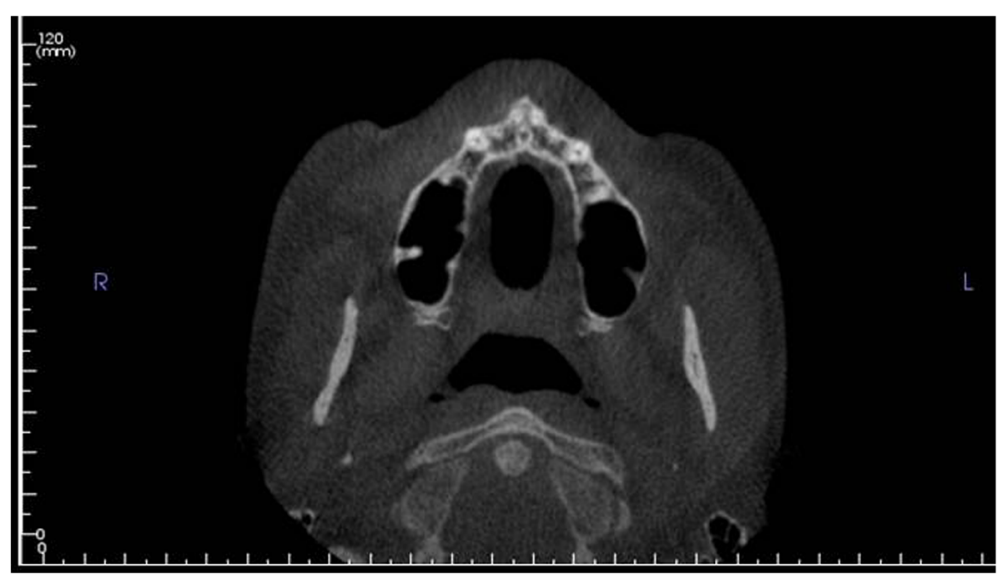

Fig. 1 Axial section depicting the localization at the level of the incisive foramen

Mean, standard deviation, and percentile distributions were computed for palatal bone thickness and palatal bone density. Power analysis showed that a sample size of at least 30 subjects per group would give an $80 \%$ probability of detecting a real difference between the groups at a statistically significant level of $5 \%$. Interexaminer reliability was computed by Cronbach alpha values. A one-sample Kolmogorov-Smirnov test was used to examine normality of distribution of the outcomes measured. The outcomes were distributed normally, and one-way ANOVA was used to determine the significance between the different sites measured in different experimental groups. Tukey's test was used for multiple comparisons between the groups. Pearson correlation coefficient $(r)$ was used to measure the correlation between the PBT and PBD in the center of the palate in different experimental groups. Kappa statistics were done to measure the intraexaminer reliability. All statistical tests were two sided, and a $P$ value of $<0.05$ was deemed to be statistically significant. The size of the total measurement error (ME) was calculated with the following formula: $\left.\mathrm{ME}=\sqrt{(\Sigma} d^{2}\right) / 2 n$ with $d$ the difference between the two measurements and $n$ the number of double measurements. The overall measurement error of the various measurements was not greater than $0.3 \mathrm{~mm}$. Statistical analyses were computed using Graph Pad software (LaJolla, CA, USA).

\section{Results}

A total of 359 patients were included in the study. This included 99 growing males (12 years and 5 months \pm 3 years and 2 months), 74 non-growing males (27 years and 1 month \pm 3 years and 9 months), 105 growing females (mean age, 13 years and 4 months \pm 2 years and 1 month), and 81 non-growing females (mean age, 31 years and 3 months \pm 4 years and 7 months). Cohen's kappa was 0.87 for the intraexaminer reliability. Distribution of PBT at different sites is summarized in Tables 1, 2, 3, and 4 . PBT was significantly lower $(P<0.0001)$ as we moved

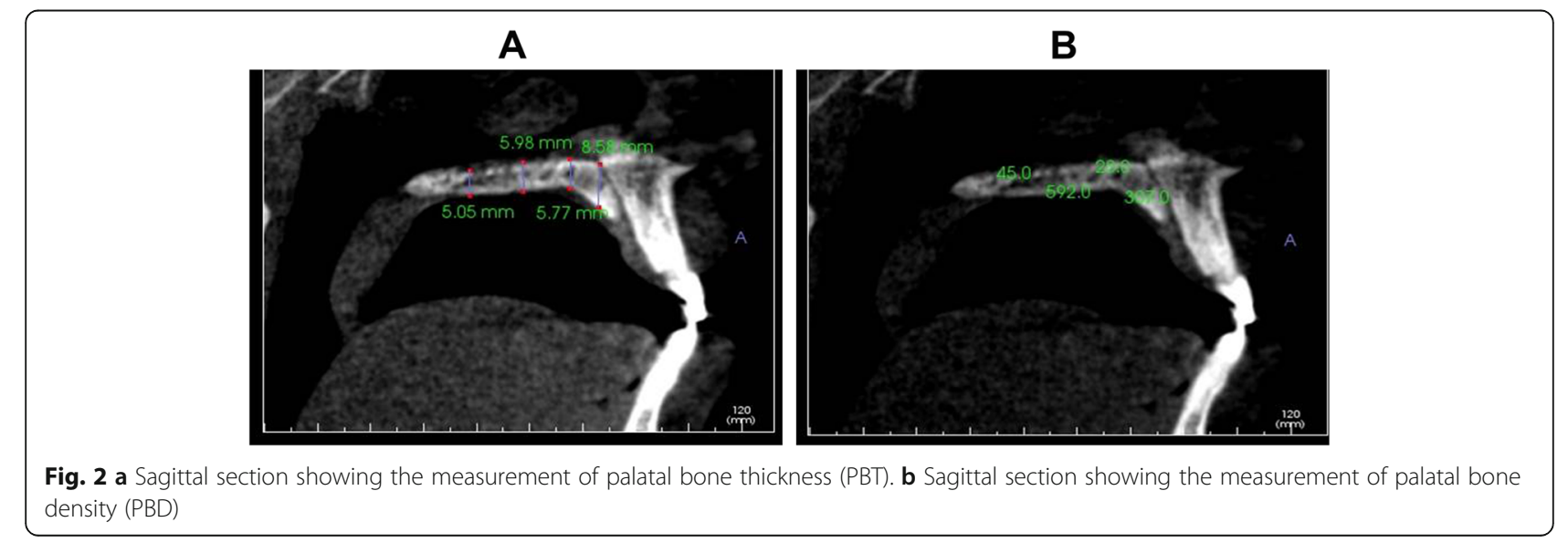


Table 1 Descriptive statistics of palatal bone thickness in growing male

\begin{tabular}{|c|c|c|c|c|c|c|c|c|}
\hline & $\begin{array}{l}\text { Canine and } \\
\text { first PM }\end{array}$ & $\begin{array}{l}\text { Canine and first } \\
\text { PM ( } 4 \mathrm{~mm})\end{array}$ & $\begin{array}{l}\text { First PM and } \\
\text { second PM }\end{array}$ & $\begin{array}{l}\text { First PM and } \\
\text { second PM } \\
(4 \mathrm{~mm})\end{array}$ & $\begin{array}{l}\text { Second PM } \\
\text { and first M }\end{array}$ & $\begin{array}{l}\text { Second PM } \\
\text { and first M } \\
(4 \mathrm{~mm})\end{array}$ & $\begin{array}{l}\text { First } M \text { and } \\
\text { second } M\end{array}$ & $\begin{array}{l}\text { First } M \text { and } \\
\text { second } M \\
(4 \mathrm{~mm})\end{array}$ \\
\hline Number of values & 99 & 99 & 99 & 99 & 99 & 99 & 99 & 99 \\
\hline Minimum & 2.89 & 5.15 & 1.51 & 1.27 & 0.92 & 1.04 & 0.97 & 0.65 \\
\hline 25\% Percentile & 6.57 & 9.5 & 5.39 & 4.01 & 3.72 & 2.47 & 3.44 & 1.44 \\
\hline Median & 8.24 & 11.4 & 6.45 & 5.37 & 5.15 & 3.43 & 4.43 & 2.26 \\
\hline 75\% Percentile & 10.04 & 14.13 & 7.62 & 7.15 & 6.57 & 4.81 & 5.82 & 3.72 \\
\hline Maximum & 13.91 & 19.06 & 11.92 & 10.99 & 11.09 & 9.3 & 11.34 & 7.66 \\
\hline Mean & 8.17 & 11.73 & 6.465 & 5.582 & 5.269 & 3.709 & 4.727 & 2.716 \\
\hline Std. deviation & 2.38 & 3.169 & 2.041 & 2.148 & 2 & 1.622 & 2.025 & 1.549 \\
\hline Std. error of mean & 0.2392 & 0.3185 & 0.2051 & 0.2159 & 0.201 & 0.163 & 0.2035 & 0.1557 \\
\hline Lower 95\% Cl & 7.696 & 11.09 & 6.058 & 5.154 & 4.87 & 3.385 & 4.323 & 2.407 \\
\hline Upper 95\% Cl & 8.645 & 12.36 & 6.872 & 6.011 & 5.667 & 4.032 & 5.131 & 3.025 \\
\hline
\end{tabular}

PM premolar, $M$ molar

from the anterior palate to the posterior palate in all the groups (Tables 1, 2, 3, and 4). The PBT was significantly $(P<0.001)$ more in the center of the palate than $4 \mathrm{~mm}$ away from the center, except in between the canine and first premolar (Tables 1, 2, 3, and 4), where the PBT was significantly lower $(P<0.05)$ in the center than $4 \mathrm{~mm}$ away from it (growing male, $8.17 \pm 2.38<11.73 \pm$ $3.16 \mathrm{~mm}$; growing female, $6.36 \pm 2.17<9.74 \pm 2.81 \mathrm{~mm}$; non-growing male, $8.29 \pm 2.88<12.63 \pm 3.38 \mathrm{~mm}$; nongrowing female, $6.79 \pm 2.64<9.57 \pm 3.01 \mathrm{~mm}$ ). The sex comparison showed significantly higher $(P<0.001)$
PBT in the male. The growing male had significantly higher $(P<0.0001)$ bone thickness than the growing female in between the canine and first premolar and between the first premolar and second premolar both in the center of the palate and $4 \mathrm{~mm}$ away from the palate (Tables 1 and 2). Similarly, non-growing male had significantly greater $(P<0.001)$ PBT than nongrowing female in between the canine and first premolar and the first premolar and second premolar both in the center of the palate and $4 \mathrm{~mm}$ away from the palate (Tables 3 and 4). Further, we were not able

Table 2 Palatal bone thickness in growing female

\begin{tabular}{|c|c|c|c|c|c|c|c|c|}
\hline & $\begin{array}{l}\text { Canine and } \\
\text { first PM }\end{array}$ & $\begin{array}{l}\text { Canine and } \\
\text { first PM } \\
(4 \mathrm{~mm})\end{array}$ & $\begin{array}{l}\text { First PM and } \\
\text { second PM }\end{array}$ & $\begin{array}{l}\text { First PM and } \\
\text { second PM } \\
(4 \mathrm{~mm})\end{array}$ & $\begin{array}{l}\text { Second PM } \\
\text { and first M }\end{array}$ & $\begin{array}{l}\text { Second PM } \\
\text { and first M } \\
(4 \mathrm{~mm})\end{array}$ & $\begin{array}{l}\text { First } M \text { and } \\
\text { second } M\end{array}$ & $\begin{array}{l}\text { First } M \text { and } \\
\text { second } M \\
(4 \mathrm{~mm})\end{array}$ \\
\hline $\begin{array}{l}\text { Number } \\
\text { of values }\end{array}$ & 105 & 105 & 105 & 105 & 105 & 105 & 105 & 105 \\
\hline Minimum & 1.29 & 3.44 & 1.98 & 0.84 & 1.34 & 0.57 & 0.9 & 0.71 \\
\hline $\begin{array}{l}25 \% \\
\text { Percentile }\end{array}$ & 4.805 & 7.695 & 4.32 & 3.26 & 3.81 & 2.295 & 3.05 & 1.475 \\
\hline Median & 6.36 & 9.73 & 5.2 & 4.5 & 4.57 & 2.96 & 3.94 & 1.89 \\
\hline $\begin{array}{l}75 \% \\
\text { Percentile }\end{array}$ & 7.91 & 11.81 & 6.775 & 5.92 & 6.055 & 4.115 & 5.27 & 2.865 \\
\hline Maximum & 11.97 & 16.28 & 10.23 & 12.22 & 9.02 & 7.24 & 9.62 & 6.04 \\
\hline Mean & 6.36 & 9.746 & 5.47 & 4.694 & 4.846 & 3.215 & 4.369 & 2.273 \\
\hline $\begin{array}{l}\text { Std. } \\
\text { deviation }\end{array}$ & 2.177 & 2.819 & 1.838 & 1.98 & 1.637 & 1.397 & 1.84 & 1.18 \\
\hline $\begin{array}{l}\text { Std. error } \\
\text { of mean }\end{array}$ & 0.2124 & 0.2751 & 0.1794 & 0.1932 & 0.1598 & 0.1363 & 0.1796 & 0.1151 \\
\hline $\begin{array}{l}\text { Lower } \\
95 \% \mathrm{Cl}\end{array}$ & 5.939 & 9.2 & 5.114 & 4.311 & 4.529 & 2.945 & 4.013 & 2.044 \\
\hline $\begin{array}{l}\text { Upper } \\
95 \% \text { Cl }\end{array}$ & 6.782 & 10.29 & 5.826 & 5.077 & 5.163 & 3.486 & 4.725 & 2.501 \\
\hline
\end{tabular}


Table 3 Descriptive statistics of palatal bone thickness in non-growing male

\begin{tabular}{lllllllll}
\hline & $\begin{array}{l}\text { Canine and } \\
\text { first PM }\end{array}$ & $\begin{array}{l}\text { Canine and } \\
\text { first PM } \\
(4 \mathrm{~mm})\end{array}$ & $\begin{array}{l}\text { First PM and } \\
\text { second PM }\end{array}$ & $\begin{array}{l}\text { First PM and } \\
\text { second PM } \\
(4 \mathrm{~mm})\end{array}$ & $\begin{array}{l}\text { Second PM } \\
\text { and first M }\end{array}$ & $\begin{array}{l}\text { Second PM } \\
\text { and first M } \\
(4 \mathrm{~mm})\end{array}$ & $\begin{array}{l}\text { First M and } \\
\text { second M }\end{array}$ & $\begin{array}{l}\text { First M and } \\
\text { second M } \\
(4 \mathrm{~mm})\end{array}$ \\
\hline Number of values & 74 & 74 & 74 & 74 & 74 & 74 & 74 & 74 \\
Minimum & 1.38 & 4.36 & 1.41 & 1.46 & 1.07 & 1.13 & 0.8 & 0.77 \\
25\% Percentile & 5.953 & 10.49 & 5.82 & 4.258 & 3.728 & 2.493 & 2.583 & 1.285 \\
Median & 8.21 & 13.14 & 6.965 & 5.845 & 5.265 & 3.645 & 3.995 & 1.94 \\
75\% Percentile & 10.22 & 14.58 & 8.229 & 7.413 & 6.485 & 4.783 & 5.665 & 2.948 \\
Maximum & 14.71 & 20.36 & 13.1 & 11.26 & 11.21 & 8.86 & 9.76 & 5.66 \\
Mean & 8.297 & 12.63 & 7.032 & 5.991 & 5.273 & 3.729 & 4.156 & 2.24 \\
Std. deviation & 2.888 & 3.385 & 2.158 & 2.291 & 2.167 & 1.559 & 2.06 & 1.139 \\
Std. error of mean & 0.3357 & 0.3935 & 0.2509 & 0.2663 & 0.2519 & 0.1812 & 0.2395 & 0.1324 \\
Lower 95\% Cl & 7.628 & 11.84 & 6.532 & 5.46 & 4.771 & 3.368 & 3.679 & 1.976 \\
Upper $95 \% \mathrm{Cl}$ & 8.966 & 13.41 & 7.532 & 6.522 & 5.775 & 4.091 & 4.633 & 2.503 \\
\hline
\end{tabular}

PM premolar, $M$ molar

to differentiate $(P>0.05)$ between the PBT between growing male and non-growing male at all the sites of measurements (Tables 1 and 3). Similarly, we were not able to differentiate $(P>0.05)$ between growing females and non-growing females (Tables 2 and 4 ).

The PBD was significantly higher $(P<0.005)$ in the canine and first premolar area in the center of the palate (Fig. 3), whereas in between the second premolar and first molar and between the first molar and second molar, it was significantly higher $(P<0.0001) 4 \mathrm{~mm}$ away from the center of the palate across all the experimental groups (Fig. 4). Growing female had a significantly higher $(P<0.05)$ PBD than growing male in the center of the palate and $4 \mathrm{~mm}$ away from the center, in all the areas except between the canine and first premolar, where we were not able to differentiate between growing female and growing male (Fig. 3). Similarly, non-growing female had a significantly higher bone density than growing male both in the center of the palate and $4 \mathrm{~mm}$ away from the center at all the sites measured, except between the canine and first premolar area (Fig. 4). As we moved laterally $(4 \mathrm{~mm}$ away from the center), the palatal bone density increased significantly $(P<0.001)$ in between the second premolar and first molar and the first molar and second molar in all the groups (Fig. 4).

The correlation between PBT and PBD at the center of the palate between the canine and first premolar, the first premolar and second premolar, the second premolar and first molar, and the first molar and second premolar was significant $(P<0.05)$ (Table 5$)$ and was negatively correlated in all the four experimental groups except in

Table 4 Palatal bone thickness in non-growing female

\begin{tabular}{|c|c|c|c|c|c|c|c|c|}
\hline & $\begin{array}{l}\text { Canine and } \\
\text { first PM }\end{array}$ & $\begin{array}{l}\text { Canine and } \\
\text { first PM } \\
(4 \mathrm{~mm})\end{array}$ & $\begin{array}{l}\text { First PM and } \\
\text { second PM }\end{array}$ & $\begin{array}{l}\text { First PM and } \\
\text { second PM } \\
(4 \mathrm{~mm})\end{array}$ & $\begin{array}{l}\text { Second PM } \\
\text { and first M }\end{array}$ & $\begin{array}{l}\text { Second PM } \\
\text { and first M } \\
(4 \mathrm{~mm})\end{array}$ & $\begin{array}{l}\text { First } \mathrm{M} \text { and } \\
\text { second } \mathrm{M}\end{array}$ & $\begin{array}{l}\text { First } M \text { and } \\
\text { second } M \\
(4 \mathrm{~mm})\end{array}$ \\
\hline Number of values & 81 & 81 & 81 & 81 & 81 & 81 & 81 & 81 \\
\hline Minimum & 1.95 & 0.88 & 1.91 & 0.94 & 1.01 & 0.84 & 0.99 & 0.69 \\
\hline 25\% Percentile & 4.565 & 7.65 & 4.165 & 2.935 & 3.485 & 2.07 & 2.88 & 1.43 \\
\hline Median & 6.5 & 9.47 & 5.19 & 4.2 & 4.59 & 2.8 & 4.09 & 2.05 \\
\hline 75\% Percentile & 8.72 & 11.37 & 6.265 & 5.595 & 5.695 & 3.81 & 5.51 & 2.94 \\
\hline Maximum & 14.69 & 17.04 & 10.79 & 9.69 & 9.99 & 6.56 & 9.44 & 5.77 \\
\hline Mean & 6.79 & 9.573 & 5.352 & 4.336 & 4.789 & 2.993 & 4.317 & 2.273 \\
\hline Std. deviation & 2.64 & 3.019 & 1.804 & 1.891 & 1.901 & 1.281 & 1.994 & 1.094 \\
\hline Std. error of mean & 0.2934 & 0.3355 & 0.2004 & 0.2101 & 0.2112 & 0.1424 & 0.2216 & 0.1215 \\
\hline Lower 95\% Cl & 6.206 & 8.906 & 4.953 & 3.918 & 4.368 & 2.71 & 3.876 & 2.031 \\
\hline Upper 95\% Cl & 7.373 & 10.24 & 5.751 & 4.754 & 5.209 & 3.277 & 4.758 & 2.515 \\
\hline
\end{tabular}


A

PBD Growing Male

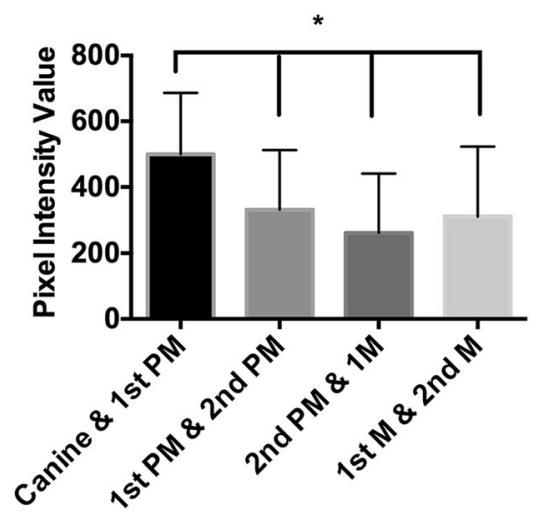

C

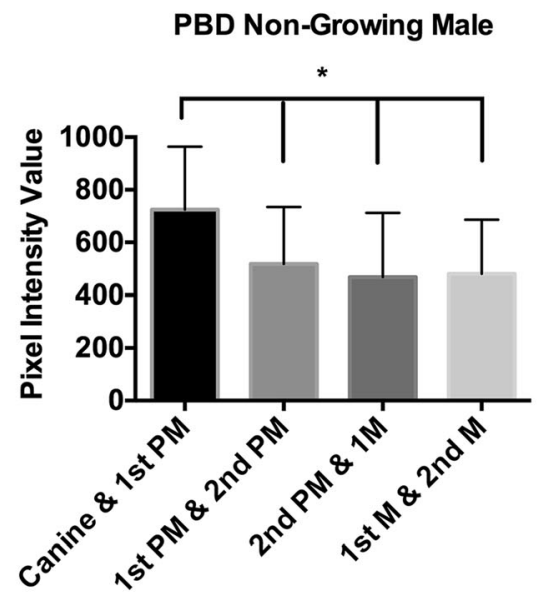

B

PBD Growing Female

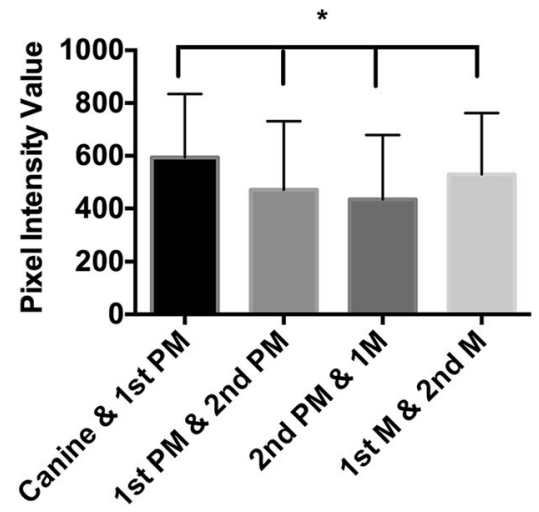

D

PBD NonGrowing Female

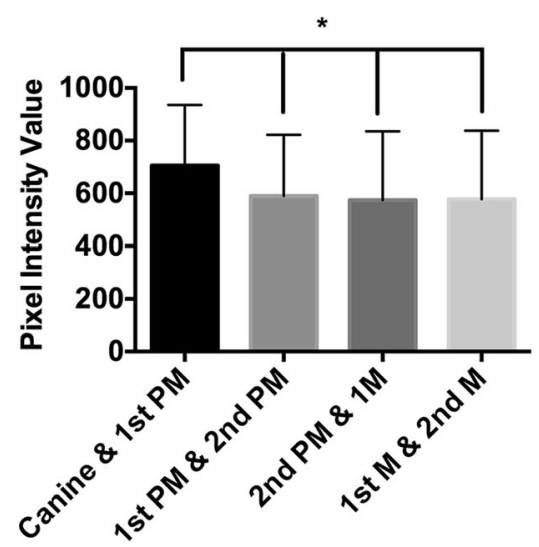

*PBD: Palatal Bone Density

Fig. 3 Bar graph showing the palatal bone density among different groups in the center of palate. a Palatal bone density in growing male at four different points measured. b Palatal bone density in growing female at four different points measured. c Palatal bone density in non-growing male at four different points measured. $\mathbf{d}$ Palatal bone density in non-growing female at four different points measured. Asterisk depicts that palatal bone density is significantly more in between the canine and first premolar when compared to other three sites measured

non-growing males in the canine and first premolar area $(P=0.9844)$ and growing males in the first premolar and second premolar area $(P=0.5363)$ (Table 5$)$.

\section{Discussion}

Skeletal anchorage has enabled clinicians to perform orthodontic tooth movement in all the three planes of space efficiently. The palatal bone has gained enormous popularity for the placement of skeletal anchorage devices for the treatment of complex malocclusions. The anatomic location of the palatal bone offers adequate keratinized soft tissue and little to no root injury during the mini-implant placement and does not interfere with majority of orthodontic tooth movement. The present study was undertaken to simultaneously evaluate both the palatal bone thickness and palatal bone density at different points in the palate using $3 \mathrm{D}$ CBCT scans. Previous studies have individually investigated either the palatal bone thickness or the palatal bone density, but none of them have studied them in similar patients and none of the previous studies have evaluated and correlated both variables (palatal bone thickness and palatal 
A

PBD Growing Male

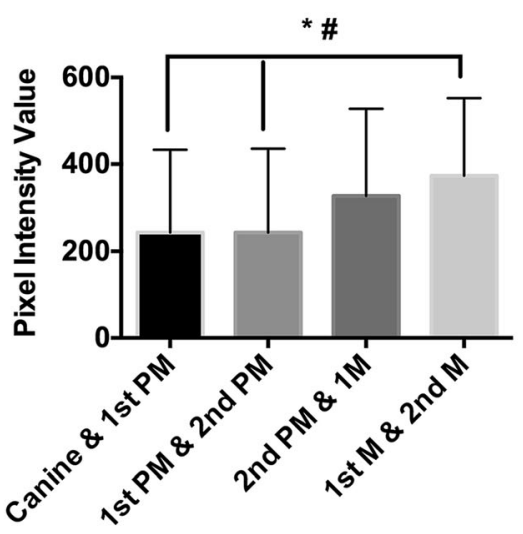

C

PBD Non-Growing Male

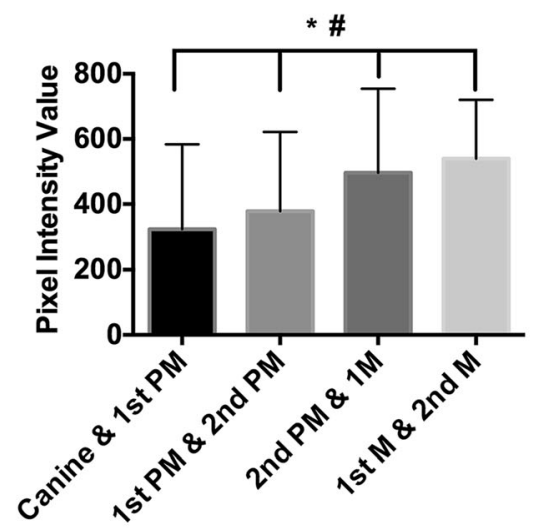

B

PBD Growing Female

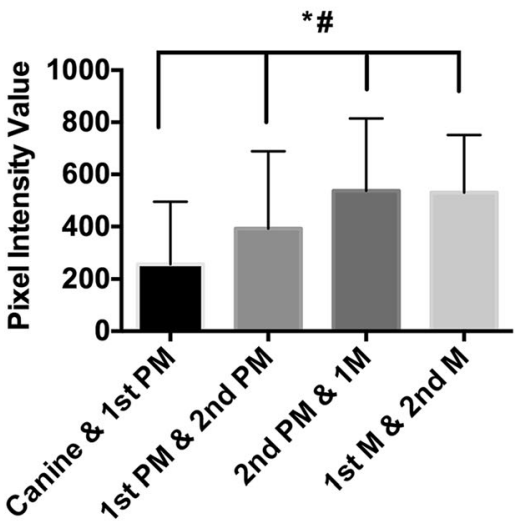

D

PBD Non-

Growing Female

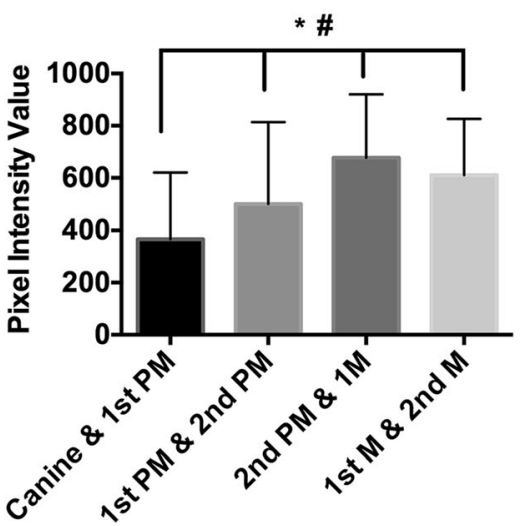

*PBD: Palatal Bone Density

Fig. 4 Bar graph showing the palatal bone density among different groups at $4 \mathrm{~mm}$ from the center of palate. a Palatal bone density in growing male at four different points measured. b Palatal bone density in growing female at four different points measured. c Palatal bone density in nongrowing male at four different points measured. $\mathbf{d}$ Palatal bone density in non-growing female at four different points measured. Asterisk depicts that palatal bone density is significantly more in between the second premolar and first when compared to other canine and first premolar and between first premolar and second premolar. Number sign depicts that palatal bone density is significantly more in between the first molar and second molar and first when compared to other canine and first premolar and between first premolar and second premolar

bone density) in different regions of the anterior, middle, and posterior palate $[1,20,24,25]$. The other important aspect of our study was our large sample size, which afforded us the ability to segment the CBCT scans into four groups and yet allow each segment to be large; thus, supporting high-quality sampling that was more representative of the population and limiting the influence of outliers or extreme observations. Further, we did measure the palatal bone density at different sites, as there exist a regional variation in the bone density in the alveolar bone.
Our null hypothesis was rejected, as there was a statistically significant variation in the PBT between the anterior, middle, and posterior part of the palate $(P<0.0001)$ as well as between the center of the palate and $4 \mathrm{~mm}$ away from the center $(P<0.001)$. The PBT decreased as we moved from the anterior palate (canine-first premolar) region to the posterior palate (first molar-second molar), as well as when we moved away from the midline. The only exception was between the canine and first premolar region where the PBT was significantly more $4 \mathrm{~mm}$ away from the center of the palate. Further, we showed that this 
Table 5 Correlation between palatal bone thickness and palatal bone density in different groups

\begin{tabular}{|c|c|c|c|c|c|}
\hline Experimental groups & Number of values (XY pairs) & Correlation coefficient & 95\% confidence interval & $P$ value & Significant \\
\hline \multicolumn{6}{|l|}{ Canine and first premolar } \\
\hline Growing male & 99 & -0.2582 & $"-0.4335$ to $-0.06405^{\prime \prime}$ & 0.0099 & Yes \\
\hline Growing female & 105 & -0.3799 & $"-0.5327$ to $-0.2030 "$ & $<0.0001$ & Yes \\
\hline Non-growing male & 74 & 0.00231 & $"-0.2263$ to $0.2307 "$ & 0.9844 & No \\
\hline Non-growing female & 81 & -0.3 & $"-0.4865$ to $-0.08735 "$ & 0.0065 & Yes \\
\hline \multicolumn{6}{|c|}{ First premolar and second premolar } \\
\hline Growing male & 99 & 0.06289 & $"-0.1362$ to $0.2571 "$ & 0.5363 & No \\
\hline Growing female & 105 & -0.3251 & $"-0.4864$ to $-0.1423 "$ & $<0.0001$ & Yes \\
\hline Non-growing male & 74 & -0.2713 & $"-0.4706$ to $-0.04561 "$ & 0.0194 & Yes \\
\hline Non-growing female & 81 & -0.352 & $"-0.5297$ to $-0.1448 "$ & 0.0013 & Yes \\
\hline \multicolumn{6}{|c|}{ First premolar and second premolar } \\
\hline Growing male & 99 & -0.2687 & $"-0.4426$ to $-0.07530 "$ & 0.0072 & Yes \\
\hline Growing female & 105 & -0.4163 & $"-0.5630$ to $-0.2441 "$ & $<0.0001$ & Yes \\
\hline Non-growing male & 74 & -0.4364 & $"-0.6046$ to $-0.2309 "$ & 0.0001 & Yes \\
\hline Non-growing female & 81 & -0.4959 & $"-0.6445$ to $-0.3112^{\prime \prime}$ & $<0.0001$ & Yes \\
\hline \multicolumn{6}{|c|}{ First molar and second molar } \\
\hline Growing male & 99 & -0.3938 & $"-0.5486$ to $-0.2129 "$ & $<0.0001$ & Yes \\
\hline Growing female & 105 & -0.4315 & $"-0.5756$ to $-0.2615 "$ & $<0.0001$ & Yes \\
\hline Non-growing male & 74 & -0.3707 & $"-0.5524$ to $-0.1553^{\prime \prime}$ & 0.0012 & Yes \\
\hline Non-growing female & 81 & -0.1825 & $"-0.3855$ to $0.03738 "$ & 0.103 & No \\
\hline
\end{tabular}

pattern was uniform in all the experimental groups. Our findings differ from the findings observed by Gracco et al., who did not find a significant difference between the bone thickness at the suture, at $3 \mathrm{~mm}$, and at $6 \mathrm{~mm}$ away from the suture in the different age groups [1]. Furthermore, we showed that we were not able to differentiate between growing males and non-growing males in the PBT at different points measured. Similarly, we were not able to differentiate between growing females and now growing females in the PBT. Kang et al. had results similar to our study, but observed the thickest bone away from the center, at the premolar region instead of the canine premolar region [25]. Further, they showed thicker bone in the middle of the palate compared to the paramedian region especially posterior to the premolar region [25]. Similar to our results, other studies have shown maximum bone thickness away from the center ( 3 to $4 \mathrm{~mm}$ away) at the canine and premolar region [26-28]. Comparison of the PBT between the males and females revealed that the males had significantly higher $(P<0.001)$ PBT than the females. The pattern of sexual dimorphism was consistent between the growing and non-growing males when compared with their respective counterparts of growing and non-growing females. Our findings were different from those of Gracco et al. and Ryu et al. where they found no gender-related differences in the bone thickness, and this could be attributed to different mean age of males and females in our study $[1,8]$. Moreover, we were unable to differentiate the PBT between the growing and non-growing populations in both the sexes. One could conclude from this finding that very little bone is formed or added after age 13 (which was our mean age for the growing population).

Bone density measured by pixel intensity values (PIV) or CT numbers on CBCT scans is a practical method to assess density from CBCT exams. While PIVs are conceptually similar to Hounsfield units (HU) that are measured on CT scans, Hounsfield units are derived values that are calculated on images obtained from multi slice CT scans based on a complex mathematical post processing formula. Since such an option is not yet computable on CBCT volumes, its best to use pixel intensity values while keeping in mind that these are not absolutely defined like the Hounsfield units but never the less are practical because many studies have previously shown that Hounsfield units and pixel intensity values have a linear relationship. With careful evaluation and by using some internal controls to define the tissue thresholds, PIV values can be a very reliable way to assess bone density [29].

The PBD was significantly higher in between the canine and first premolar area in the center of the palate in all the four experimental groups. Similarly, the PBD was significantly higher in between the second 
premolar and first molar and the first molar and second molar at $4 \mathrm{~mm}$ away from the palate in all the experimental groups. The bone density was higher as there was more cortical bone present (Fig. 2a, b) in the canine and first premolar region (center of palate). We also found considerable variation in the PBD value within each group, like the previous studies; however, given our much larger sample size, it is safe to assume that our group means are more precise and represent the population [24]. Surprisingly, our finding shows that growing female and non-growing female had more $\mathrm{PBD}$ than growing male and non-growing male respectively. The bone matrix of the newly formed bone is less mineralized, and subsequent primary and secondary mineralization (increase in bone density) continues for years after the growth (increase in bone thickness). In our research, the mean age of growing females/non-growing females was more than the mean age of the growing males/non-growing males, and after bone formation, the mineral content rapidly increases up to $70 \%$ of full mineralization within 1 month of bone formation, but secondary mineralization which contributes to $30 \%$ of mineralization lasts for years and probably females being older in our sample size had more secondary mineralization [30, 31]. Moreover, approximately $8 \%$ of bone turnover (bone remodeling) occurs annually and bone turnover is activated at different time points in each individual [32]. Further, non-growers (male and female) had significantly more palatal bone density than their growing counterparts. Similarly, Han et al. showed significantly higher bone density in adults than in adolescents [24].

\section{Clinical significance}

The PBT and PBD vary between males and females. The palatal bone thickness was higher in the anterior part of the palate (between the canine and first premolar), so there are chances that bone to mini-implant contact area will be more; thus, primary stability of the mini-implant will be more. However, at the same time, the palatal bone density is highest in between the canine and first premolar area, thus will require higher torque for the insertion of mini-implants. Our suggestion will be to place the mini-implants with increased diameter in the anterior part of the palate (good bone quality and quantity) to prevent fracture of the mini-implants.

\section{Conclusions}

1. The anterior part of the palatal bone has the highest bone thickness (bone quantity) in all the four groups. Growing males had significantly higher bone thickness when compared to growing females between the canine and first premolar and between the first premolar and second premolar. Similarly, non-growing male has the higher bone thickness when compared to growing and non-growing female.

2. Non-growing males and non-growing females had a significantly higher bone density in the center of the palate at all the four sites of measurements, when compared to growing males and growing females respectively.

3. Bone density was significantly higher in between the second premolar and first molar and between the first molar and second molar in all the four experimental groups, $4 \mathrm{~mm}$ away from the palate.

\section{Availability of data and materials}

The data is available with the PI (Sumit Yadav), and raw cone beam computed tomograms are also available with the PI (Sumit Yadav).

\section{Author's contributions}

$\mathrm{RN}, \mathrm{SY}, \mathrm{AT}$, and $\mathrm{MU}$ contributed to the conceptualization and methodology. $E S, K K, M V, A T$, and SY contributed to the data collection. RN, AT, MU, SY, KK, and MV contributed to the interpretation of the data. ES, RN, AT, MU, SY, KK, and MV contributed to the manuscript preparation. ES, RN, AT, MU, SY, KK, and $\mathrm{MV}$ contributed to the final approval of the manuscript.

\section{Ethics approval and consent to participate}

An institutional review board (IRB) exemption was obtained for evaluating CBCT volumes archived in the Department of Oral and Maxillofacial Radiology. The

IRB exemption was obtained from University of Connecticut Health Center.

\section{Consent for publication}

Not applicable

Competing interests

The authors declare that they have no competing interests.

\section{Publisher's Note}

Springer Nature remains neutral with regard to jurisdictional claims in published maps and institutional affiliations.

\section{Author details}

'Division of Orthodontics, University of Connecticut Health Center, Farmington, USA. ${ }^{2}$ School of Dental Medicine, University of Connecticut Health Center, 263 Farmington Avenue, L7062A MC1725, Farmington, CT 06030, USA. ${ }^{3}$ Division of Orthodontics, University of Nebraska Medical Center, Farmington, USA. ${ }^{4}$ Private Practice, Houston, Texas, USA. ${ }^{5}$ Division of Oral Health and Diagnostic Sciences, University of Connecticut Health Center, Farmington, USA.

Received: 12 April 2018 Accepted: 7 September 2018

Published online: 05 November 2018

\section{References}

1. Gracco A, Lombardo L, Cozzani M, Siciliani G. Quantitative cone-beam computed tomography evaluation of palatal bone thickness for orthodontic miniscrew placement. Am J Orthod Dentofac Orthop. 2008;134(3):361-9.

2. Deguchi T, Nasu M, Murakami K, Yabuuchi T, Kamioka H, Takano-Yamamoto T. Quantitative evaluation of cortical bone thickness with computed tomographic scanning for orthodontic implants. Am J Orthod Dentofacial Orthop. 2006;129(6):721 e7-12.

3. Uribe F, Mehr R, Mathur A, Janakiraman N, Allareddy V. Failure rates of miniimplants placed in the infrazygomatic region. Prog Orthod. 2015;16:31.

4. Kalra S, Tripathi T, Rai P, Kanase A. Evaluation of orthodontic mini-implant placement: a CBCT study. Prog Orthod. 2014;15:61. 
5. Sivamurthy G, Sundari S. Stress distribution patterns at mini-implant site during retraction and intrusion--a three-dimensional finite element study. Prog Orthod. 2016;17:4.

6. Hilscher WM, Trott KR, Hilscher W. Cell progression and radiosensitivity of T1-prospermatogonia in Wistar rats. Int J Radiat Biol Relat Stud Phys Chem Med. 1982:41(5):517-24.

7. Kassem HE, Marzouk ES. Prediction of changes due to mandibular autorotation following miniplate-anchored intrusion of maxillary posterior teeth in open bite cases. Prog Orthod. 2018;19(1):13.

8. Ryu JH, Park JH, Vu Thi Thu T, Bayome M, Kim Y, Kook YA. Palatal bone thickness compared with cone-beam computed tomography in adolescents and adults for mini-implant placement. Am J Orthod Dentofac Orthop. 2012;142(2):207-12.

9. Baumgaertel S. Quantitative investigation of palatal bone depth and cortical bone thickness for mini-implant placement in adults. Am J Orthod Dentofac Orthop. 2009;136(1):104-8.

10. Arcuri C, Muzzi F, Santini F, Barlattani A, Giancotti A. Five years of experience using palatal mini-implants for orthodontic anchorage. J Oral Maxillofac Surg. 2007:65(12):2492-7.

11. Sommerfeldt DW, Rubin CT. Biology of bone and how it orchestrates the form and function of the skeleton. Eur Spine J. 2001;10(Suppl 2): S86-95.

12. Frost HM. Skeletal structural adaptations to mechanical usage (SATMU): 1 Redefining Wolff's law: the bone modeling problem. Anat Rec. 1990;226(4): 403-13.

13. Frost HM. Wolff's law and bone's structural adaptations to mechanical usage: an overview for clinicians. Angle Orthod. 1994;64(3):175-88.

14. Karagkiolidou A, Ludwig B, Pazera P, Gkantidis N, Pandis N, Katsaros C. Survival of palatal miniscrews used for orthodontic appliance anchorage: a retrospective cohort study. Am J Orthod Dentofac Orthop. 2013;143(6):767-72.

15. Manni A, Cozzani M, Tamborrino F, De Rinaldis S, Menini A. Factors influencing the stability of miniscrews. A retrospective study on 300 miniscrews. Eur J Orthod. 2011:33(4):388-95.

16. Andruch $K$, Plachta A. Evaluating maxilla bone quality through clinical investigation of voxel grey scale values from cone-beam computed tomography for dental use. Adv Clin Exp Med. 2015;24(6):1071-7.

17. Fuster-Torres MA, Penarrocha-Diago M, Penarrocha-Oltra D, PenarrochaDiago M. Relationships between bone density values from cone beam computed tomography, maximum insertion torque, and resonance frequency analysis at implant placement: a pilot study. Int J Oral Maxillofac Implants. 2011;26(5):1051-6.

18. Cassetta M, Stefanelli LV, Pacifici A, Pacifici L, Barbato E. How accurate is $\mathrm{CBCT}$ in measuring bone density? A comparative CBCT-CT in vitro study. Clin Implant Dent Relat Res. 2014;16(4):471-8.

19. Kim DG. Can dental cone beam computed tomography assess bone mineral density? J Bone Metab. 2014;21(2):117-26.

20. Campos MJ, de Souza TS, Mota Junior SL, Fraga MR, Vitral RW. Bone mineral density in cone beam computed tomography: only a few shades of gray. World J Radiol. 2014;6(8):607-12.

21. Hsu JT, Chen YJ, Tsai MT, Lan HH, Cheng FC, Chen MY, et al. Predicting cortical bone strength from DXA and dental cone-beam CT. PLoS One. 2012;7(11):e50008

22. Hohlweg-Majert B, Metzger MC, Kummer T, Schulze D. Morphometric analysis - cone beam computed tomography to predict bone quality and quantity. J Craniomaxillofac Surg. 2011;39(5):330-4.

23. Mueller TL, van Lenthe $\mathrm{GH}$, Stauber M, Gratzke C, Eckstein F, Muller R Regional, age and gender differences in architectural measures of bone quality and their correlation to bone mechanical competence in the human radius of an elderly population. Bone. 2009;45(5):882-91.

24. Han S, Bayome M, Lee J, Lee YJ, Song HH, Kook YA. Evaluation of palatal bone density in adults and adolescents for application of skeletal anchorage devices. Angle Orthod. 2012;82(4):625-31.

25. Kang S, Lee SJ, Ahn SJ, Heo MS, Kim TW. Bone thickness of the palate for orthodontic mini-implant anchorage in adults. Am J Orthod Dentofac Orthop. 2007;131(4 Suppl):S74-81.

26. King KS, Lam EW, Faulkner MG, Heo G, Major PW. Predictive factors of vertical bone depth in the paramedian palate of adolescents. Angle Orthod. 2006;76(5):745-51
27. Lai RF, Zou H, Kong WD, Lin W. Applied anatomic site study of palatal anchorage implants using cone beam computed tomography. Int J Oral Sci. 2010;2(2):98-104.

28. Bernhart T, Vollgruber A, Gahleitner A, Dortbudak O, Haas R. Alternative to the median region of the palate for placement of an orthodontic implant. Clin Oral Implants Res. 2000;11(6):595-601.

29. Oliveira ML, Tosoni GM, Lindsey DH, Mendoza K, Tetradis S, Mallya SM. Assessment of CT numbers in limited and medium field-of-view scans taken using Accuitomo 170 and Veraviewepocs 3De cone-beam computed tomography scanners. Imaging Sci Dent. 2014;44(4):279-85.

30. Roschger $\mathrm{P}$, Paschalis EP, Fratzl $\mathrm{P}$, Klaushofer K. Bone mineralization density distribution in health and disease. Bone. 2008;42(3):456-66.

31. Boivin G, Meunier PJ. Methodological considerations in measurement of bone mineral content. Osteoporos Int. 2003;14(Suppl 5):S22-7 discussion S7-8.

32. Allen MR, Turek JJ, Phipps RJ, Burr DB. Greater magnitude of turnover suppression occurs earlier after treatment initiation with risedronate than alendronate. Bone. 2011;49(1):128-32

\section{Submit your manuscript to a SpringerOpen ${ }^{\circ}$ journal and benefit from:}

- Convenient online submission

- Rigorous peer review

- Open access: articles freely available online

- High visibility within the field

- Retaining the copyright to your article

Submit your next manuscript at $>$ springeropen.com 